Retrospective Study

\title{
Radiculopathy Following Vertebral Body Compression Fracture: The Role of Percutaneous Cement Augmentation
}

David Gimarc, MD¹, Alexandria Jensen, MS¹, Kimberly Lind, PhD², and Mary K. Jesse, MD

From: ${ }^{2}$ University of Colorado Denver, Anschutz Medical Campus, Aurora, $\mathrm{CO} ;{ }^{2}$ Australian Institute of Health Innovation,

Macquarie Park, North Ryde NSW, Australia

Address Correspondence: David Gimarc, MD

University of Colorado Anschutz Medical Campus 12631 East 17th Ave., Rm 2414 Aurora, CO 80045 E-mail:

David.gimarc@ucdenver.edu

Disclaimer: There was no external funding in the preparation of this manuscript.

Conflict of interest: Each author certifies that he or she, or a member of his or her immediate family, has no commercial association (i.e., consultancies, stock ownership, equity interest, patent/licensing arrangements, etc.) that might pose a conflict of interest in connection with the submitted manuscript.

Manuscript received: 08-03-2018 Revised manuscript received: 10-01-2019 Accepted for publication: 10-18-2019

Free full manuscript: www.painphysicianjournal.com
Background: Vertebral cement augmentation is a commonly used procedure in patients with vertebral body compression fractures from primary or secondary osteoporosis, metastatic disease, or trauma. Many of these patients present with radiculopathy as a presenting symptom, and can experience symptomatic relief following the procedure.

Objectives: To determine the incidence of preprocedural radiculopathy in patients with vertebral body compression fractures presenting for cement augmentation, and present their postoperative outcomes.

Study Design: Retrospective cohort study.

Setting: Interventional pain practice in a tertiary care university hospital.

Methods: In this cohort study, all patients who underwent kyphoplasty (KP) or vertebroplasty (VP) procedures in a 7-year period within our practice were evaluated through a search of the electronic medical records. The primary endpoint was to evaluate the prevalence of noncompressive preprocedural radiculopathy in our patients. Evaluation of each patient's relative improvement following the procedure, respective to the initial presence or absence of radicular symptoms (including and above T10, above and below T10, and below T10) was included as a secondary endpoint. Additional subanalysis was performed with respect to patients demographics, fracture location, and primary indication for the procedure (osteoporosis, trauma, etc.).

Results: A total of 302 procedures were performed during this time period, encompassing 544 total vertebral body levels. After exclusion criteria were applied to this cohort, $31.6 \%$ of patients demonstrated radiculopathy prior to the procedure that could not be explained by nerve impingement. Nearly half of patients demonstrated an optimal clinical outcome $(48.5 \%$ nearly complete/complete resolution of symptoms, $40.1 \%$ partial resolution of symptoms, $11.4 \%$ little to no resolution of symptoms). Patients with fractures above T10 were more likely to see complete resolution, whereas patients with fractures above and below T10 were likely to not see any resolution. Men and women without initial radiculopathy symptoms were more likely to see little to no resolution, regardless of fracture location.

Limitations: This retrospective study used an electronic chart review of clinicians' notes to determine the presence of radiculopathy and their relative improvement following the procedure.

Conclusions: Preprocedural radiculopathy is a common symptom of patients presenting for the evaluation of VP or KP. The presence of radiculopathy in the absence of nerve impingement may be an important marker for those patients who may experience greater benefit from the procedure.

Key words: Radiculopathy, kyphoplasty, vertebroplasty, osteoporosis, compression fracture, spine, cement augmentation

Pain Physician 2020: 23:315-323 


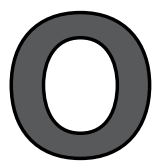

steoporosis affects millions of people around the world, placing many at risk of insufficiency fractures of the axial and appendicular skeleton (1). In patients with osteoporosis, vertebral body compression fractures (VCFs) represent a large number of insufficiency fractures, with 700,000 cases per year, and over 100,000 hospitalizations occurring as a result of VCF in the United States alone (2). Interest in the rapid and effective treatment of VCF has increased not only as a response to our aging population, but also as a result of the increased morbidity and mortality associated with VCF attributed to worsened pulmonary status, immobility, and overall decreased quality of life (2-4).

Vertebroplasty (VP) and balloon kyphoplasty (KP) are percutaneous methods to treat vertebral compression fractures in which polymethylmethacrylate (PMMA) cement is administered into the fractured vertebra. Introduced in the 1980s, VP and KP have remained a commonly used treatment for VCF due to osteoporosis, pathologic fractures, or trauma largely because of the minimally invasive approach and more rapid healing relative to surgical and conservative alternatives (5-14). Recent randomized controlled trials demonstrating the clear benefit of VP and KP over conservative therapy likely account for the increased use of the procedure in recent years (15-28).

The presentation of vertebral compression fracture is classically described as axial back pain localizing to the level of fracture (8) but, in our experience at our institution, patients with acute VCFs often present with a radicular component to their pain. This radicular symptom frequently occurs in the absence of mechanical nerve compression or neural foraminal compromise. Several articles, including the 2014 Society of Interventional Radiology practice guidelines, have classified radiculopathy as a relative contraindication to performing VP/KP, owing to an assumed mechanical compression of nerve roots from vertebral body fracture fragments $(8,29-31)$. This classification creates a treatment dilemma in a large subset of patients in whom noncompressive radiculopathy coincides with their fracture pain. Although relative contraindications offer some room for interpretation and clinical judgement, these guidelines may lead physicians to unnecessarily exclude patients with noncompressive radiculopathy from obtaining the procedure.

In this single-site, retrospective study, we aim to better understand the prevalence of noncompressive preprocedural radiculopathy in our VCF patient population, and further assess the expected outcomes following VP/KP treatment in this subset of patients. We hypothesize that the presence of radiculopathy alone is not an exclusive contraindication for identifying appropriate patient populations, but rather a potential method of identifying patients, which may show increased benefit from undergoing percutaneous cement augmentation.

\section{Methods}

\section{Study Design and Patient Selection}

This is a retrospective cohort study of all KP and VP procedures performed at a large single-site academic medical center over a 7-year period. Preand postprocedural clinical notes within our institution's electronic medical records (EMR) system were scrutinized to determine the presence or absence of preprocedural radiculopathy with onset at the time of fracture, as well as an assessment of baseline pain level. The location of the fracture, number of fractured levels, underlying bone pathology, and demographics were recorded for each patient case.

\section{VP and KP Technique}

Patients were selected to undergo a VP or KP based on the presence of (an) acute $\operatorname{VCF}(\mathrm{s})$ with associated back pain using accepted indications $(32,33)$. Acute compression fracture was determined by the presence of a new vertebral fracture in short interval follow-up or the presence of an edematous vertebral body on magnetic resonance imaging of the spine. All VP and KP procedures were performed by the same 3 fellowship-trained musculoskeletal radiologists at a single academic medical center using a Siemens Axiom Artis biplane fluoroscopy unit (Siemens, Munich, Germany). Over the 7-year study period, various vendors' equipment was used with an overwhelmingly predominant use of the Stryker vertebroplasty and kyphoplasty system (Stryker, Kalamazoo, MI).

All operators used the same cement augmentation technique, which involved placement of unipedicular or bipedicular 10 to $13 \mathrm{G}$ access trocars into the fractured vertebral bodies. During balloon augmentation, 10 to $20 \mathrm{~mm}$ balloons were placed via the indwelling trocars and inflated to a maximum of 400 psi. Moderate to high viscosity PMMA was instilled with manual injection under direct visualization. 


\section{Data Collection/Analyses}

Pre- and postprocedural pain levels were defined via the Visual Analog Scale (VAS). During routine pre- and postprocedural clinical assessment, patients were asked to rank their perceived pain on a 1 to 10 scale, with "10" being the most severe and "1" being the least severe. Pre- and postprocedural VAS pain levels were compared and symptomatic improvement was classified as "little to none" (<25\% improvement in VAS), "partial" ( $25 \%$ $74 \%$ improvement in VAS), "near complete" (75\%-99\% improvement in VAS), and "complete" (100\% improvement in VAS), based on VAS improvement or subjective comments made by patients and practitioners within the EMR postprocedural follow-up notes. Optimal outcomes were considered only when "near complete" or "complete" pain relief was achieved.

Radiculopathy was defined as a patient complaint of pain, numbness, or weakness in a pattern corresponding to the specific nerve distribution, and within one vertebral level of the acute VCF. Underlying pathology was classified as primary osteoporosis, pathologic fracture owing to malignancy, fracture due to acute trauma, and secondary osteoporosis from chronic steroid or epilepsy medication.

Symptoms were compared with VCF level. Patients were considered for the radiculopathy subset if radicular symptoms presented at the same time of the fracture and corresponded to a nerve distribution within one vertebral segment of the fractured level. Patients in which radicular symptoms were discordant to the level of fracture (i.e., thoracic fracture with lumbar level radiculopathy) or radiculopathy that was present before the fracture event were considered to have no concordant radiculopathy, and therefore were not included in the radiculopathy subset. Patients were required to obtain preprocedural cross-sectional imaging of the affected spine to assess for the presence and severity of neural foraminal stenosis as a possible confounding cause of radiculopathy, such as mechanical compression from fracture fragments. Patients with "moderate to severe" or "severe" neural foraminal stenosis at the levels of interest were excluded from the sample because of the presumed mechanical impingement of the exiting nerve. Patients without preprocedural cross-sectional imaging and patients lost to follow-up were also excluded. This exclusion provided a subset of noncompressive radiculopathy patients in whom there was no apparent mechanical cause of the radicular pain.

Fracture location was subdivided into those above and including T10, and those below T10. The T10 level was chosen for the level of subdivision as this level most accurately defines the transition between thoracic kyphosis and lumbar lordosis, and thus the change in spine mechanics. A small subset of patients presented with concomitant fractures above and below the T10 level. These patients were placed in a third subset defined as "above and below T10" as to not overrepresent these patients in one or both subsets.

\section{Statistical Methods}

Descriptive statistics, including mean, standard deviation, range, and frequencies, were calculated overall and by resolution category. All analyses were performed in SAS version 9.4 (SAS Institute, Cary, NC), and all statistical tests used a type I error rate of 0.05 . Ordinal multivariable logistic regression was used to model the ordered 3-level outcome of symptom resolution (unchanged, partial resolution, near complete/ complete resolution). The primary predictor of interest was a binary indicator for presence of radiculopathy. Covariates evaluated included patient age, gender, categorical fracture level (above T10, below T10, or both above and below T10), categorical number of levels on which the procedure was performed (with 3 or more levels collapsed into a single category of 3+), and comorbidities of cancer, osteoporosis, diabetes mellitus, and trauma. A backward stepwise model building approach was used. Interactions were retained if their parameter estimate had an associated $P$ value $<0.05$, and comorbid and procedure level main effects were retained if they had an associated $P$ value $<0.20$. Odds ratios, $95 \%$ confidence intervals for the odds ratios, and $P$ values were produced for the final reduced model. Additionally, predicted probabilities for the no resolution, partial resolution, and near complete/ complete resolution outcomes were calculated for the marginal patient.

\section{Results}

A total of $302 \mathrm{KP}$ and VP procedures were performed at our institution in the 7-year study period, encompassing 544 vertebral body levels. Fourteen patients were excluded as they were lost to follow-up after the procedure. An additional 11 patients were excluded due to nonconcordant symptoms, either due to discordant location of symptoms or onset of symptoms. A further 5 patients were excluded due to moderate to severe or severe neural foraminal stenosis at the levels of interest corresponding to their radiculopathy symptoms. Following the exclusion criteria, 272 pa- 
Table 1. Sample characteristics overall and by radiculopathy resolution category.

\begin{tabular}{|c|c|c|c|c|}
\hline & $\mathrm{n}=\mathbf{2 7 2}$ & $\mathbf{n}=\mathbf{3 1}$ & $\mathrm{n}=109$ & $\mathrm{n}=132$ \\
\hline Variable & Overall & Unchanged & Partial & Complete/near \\
\hline \multicolumn{5}{|l|}{ Age } \\
\hline Mean (SD) & $66.81(13.44)$ & $66.29(13.96)$ & $63.52(14.61)$ & $69.65(11.65)$ \\
\hline \multirow[t]{2}{*}{ Range } & $23-95$ & $27-94$ & $23-93$ & $26-95$ \\
\hline & $\begin{array}{l}\text { Frequency } \\
\text { (Col \%) }\end{array}$ & $\begin{array}{c}\text { Frequency } \\
\text { (Row \%, Col \%) }\end{array}$ & $\begin{array}{c}\text { Frequency } \\
\text { (Row \%, Col \%) }\end{array}$ & $\begin{array}{c}\text { Frequency } \\
(\text { Row \%, Col \%) }\end{array}$ \\
\hline \multicolumn{5}{|l|}{ Sex } \\
\hline Female & 147 (54.04\%) & $18(12.24 \%, 58.06 \%)$ & $56(38.10 \%, 51.38 \%)$ & $73(49.66 \%, 55.30 \%)$ \\
\hline Male & $125(45.96 \%)$ & $13(10.40 \%, 41.94 \%)$ & $53(42.40 \%, 48.62 \%)$ & $59(47.20 \%, 44.70 \%)$ \\
\hline \multicolumn{5}{|l|}{ Radiculopathy } \\
\hline Present & $86(31.61 \%)$ & $6(6.98 \%, 19.35 \%)$ & $34(39.53 \%, 31.19 \%)$ & $46(53.49 \%, 34.85 \%)$ \\
\hline Absent & $186(68.38 \%)$ & $25(13.44 \%, 80.65 \%)$ & $75(40.32 \%, 68.81 \%)$ & $86(46.24 \%, 65.15 \%)$ \\
\hline \multicolumn{5}{|l|}{ Condition } \\
\hline Primary Osteoporosis & $152(55.88 \%)$ & $20(13.16 \%, 64.52 \%)$ & $50(32.89 \%, 45.87 \%)$ & $82(53.95 \%, 62.12 \%)$ \\
\hline Secondary Osteoporosis & $45(16.54 \%)$ & $7(15.16 \%, 22.58 \%)$ & $21(46.67 \%, 19.27 \%)$ & $17(37.78 \%, 12.88 \%)$ \\
\hline Cancer & $66(24.26 \%)$ & $3(4.55 \%, 9.68 \%)$ & $34(51.52 \%, 31.19 \%)$ & $29(43.94 \%, 21.97 \%)$ \\
\hline Trauma & $9(3.31 \%)$ & $1(11.11 \%, 3.23 \%)$ & $4(44.44 \%, 3.67 \%)$ & $4(44.44 \%, 3.03 \%)$ \\
\hline \multicolumn{5}{|l|}{ Fracture Characteristics } \\
\hline \multicolumn{5}{|l|}{ Number of levels affected } \\
\hline 1 & $134(49.26 \%)$ & $15(11.19 \%, 48.39 \%)$ & $45(33.58 \%, 41.28 \%)$ & $74(55.22 \%, 56.06 \%)$ \\
\hline 2 & $74(27.21 \%)$ & $9(12.16 \%, 29.03 \%)$ & $39(52.70 \%, 35.78 \%)$ & $26(35.14 \%, 19.70 \%)$ \\
\hline $3+$ & $64(23.52 \%)$ & $7(10.94 \%, 22.58 \%)$ & $25(39.06 \%, 22.93 \%)$ & $32(50.00 \%, 24.24 \%)$ \\
\hline \multicolumn{5}{|l|}{ Above or below T10 } \\
\hline T10 or lower affected & $62(22.79 \%)$ & $5(8.06 \%, 16.13 \%)$ & $20(32.26 \%, 18.35 \%)$ & $37(59.68 \%, 28.03 \%)$ \\
\hline Above T10 affected & $174(63.97 \%)$ & $19(10.92 \%, 61.29 \%)$ & $74(42.53 \%, 67.89 \%)$ & $81(46.55 \%, 61.36 \%)$ \\
\hline Fractures above and below T10 & $36(13.24 \%)$ & $7(19.44 \%, 22.58 \%)$ & $15(41.67 \%, 13.76 \%)$ & $14(38.89 \%, 10.61 \%)$ \\
\hline
\end{tabular}

tients remained within the cohort. Table 1 details the demographics of the sample both overall and by resolution category. The average patient age was 66.8 years (range, 25-95 years) with a male to female ratio of 125:147.

Fifty percent of cases involved fractures at more than one level, with the largest case involving 5 levels. Underlying etiology of fracture included primary osteoporosis $(55.9 \%)$, pathologic fracture of malignancy $(24.2 \%)$, and secondary osteoporosis $(16.5 \%)$. The thoracic spine above T10 was the most common general location (64.0\%), although the L1 level was the most common single level involved (15.4\%).

Eighty-six patients $(31.6 \%)$ within the final cohort exhibited symptomatic radiculopathy, concordant to the level of acute fracture with onset at the time of fracture.

A total of 132 patients $(48.5 \%)$ had complete to nearly complete resolution of their symptoms after the procedure, $109(40.1 \%)$ had partial resolution, and only $31(11.4 \%)$ judged their symptoms to be unchanged or with little to no improvement. Incidence of radiculopathy, stratified by gender and location of fracture, is presented in Table 2. Additional information on the frequency of radiculopathy by outcome level, stratified by gender, is presented in Table 3 .

Convergence criteria were met for all models fit with the reduced model having a smaller Akaike information criterion (AIC) than either the full or interceptonly models. The proportional odds assumption was 
met for all models. The final reduced ordinal multivariable logistic regression results are presented in Table 4. The final model included concordant radiculopathy, age, gender, fracture location, and the interaction between gender and radiculopathy as covariates in addition to the primary covariate of interest.

Table 5 provides mean predicted probabilities for the marginal patient belonging to 1 of 3 outcomes, given various characteristics. For all marginal patients, these probabilities were calculated using the total sample's mean age ( 66.81 years). Table 5 shows that patients with fractures solely below T10 are more likely to see complete resolution, across gender and presence of radiculopathy symptoms. Conversely, patients with fractures both above and below T10 are the most likely to not see any resolution, controlling for gender and presence of radiculopathy symptoms.

Men and women without radiculopathy symptoms were most likely to see no resolution than those with radiculopathy, regardless of the fracture location(s).

\section{Discussion}

VP and balloon KP are safe and accepted methods to manage and treat symptomatic vertebral compres- sion fractures as a result of primary and secondary osteoporosis, metastatic disease, and trauma (6,34-38). The etiology of a VCF varies, although the largest contributory factor remains primary osteoporosis (37). It is estimated that $26 \%$ of women over the age of 50 years and $40 \%$ of women over the age of 80 years will suffer pain from osteoporotic VCF (39). Despite the high prevalence of osteoporotic VCFs in our society, the expected location and presentation of VCF pain has

Table 2. Radiculopathy by location.

\begin{tabular}{|l|c|c||}
\hline & $\begin{array}{c}\text { Radiculopathy } \\
\text { Present }\end{array}$ & $\begin{array}{c}\text { Radiculopathy } \\
\text { Absent }\end{array}$ \\
\hline Females & $\mathrm{n}($ Row $\%)$ & $\mathrm{n}($ Row $\%)$ \\
\hline Below T10 only & $16(40.00 \%)$ & $24(60.00 \%)$ \\
\hline Above and below T10 & $3(21.42 \%)$ & $11(78.57 \%)$ \\
\hline Above T10 only & $30(32.26 \%)$ & $63(67.74 \%)$ \\
\hline Males & $\mathrm{n}($ Row $\%)$ & $\mathrm{n}($ Row $\%)$ \\
\hline Below T10 only & $5(22.72 \%)$ & $17(77.27 \%)$ \\
\hline Above and below T10 & $5(22.72 \%)$ & $17(77.27 \%)$ \\
\hline Above T10 only & $27(33.33 \%)$ & $54(66.66 \%)$ \\
\hline
\end{tabular}

Table 3. Radiculopathy by outcome level, stratified by sex.

\begin{tabular}{|c|c|c|c|c|}
\hline Females & Overall & Unchanged & Partial & Complete/Near \\
\hline Radiculopathy & $\mathrm{n}(\mathrm{Col} \%)$ & $\mathrm{n}($ Row \%) & $\mathrm{n}($ Row \%) & $\mathrm{n}($ Row \%) \\
\hline Below T10 only & $16(32.65 \%)$ & $0(0.00 \%)$ & $2(12.50 \%)$ & $14(87.50 \%)$ \\
\hline Above and below T10 & $3(6.12 \%)$ & $0(0.00 \%)$ & $2(66.67 \%)$ & $1(33.33 \%)$ \\
\hline Above T10 only & $30(61.22 \%)$ & $2(6.67 \%)$ & $14(46.67 \%)$ & $14(46.67 \%)$ \\
\hline \multicolumn{5}{|l|}{ No Radiculopathy } \\
\hline Below T10 only & $24(24.49 \%)$ & $3(12.50 \%)$ & $8(33.33 \%)$ & $13(54.17 \%)$ \\
\hline Above and below T10 & $11(11.22)$ & $4(36.36 \%)$ & $4(36.36 \%)$ & $3(27.27 \%)$ \\
\hline Above T10 only & $63(64.29 \%)$ & $9(14.29 \%)$ & $26(41.27 \%)$ & $28(44.44 \%)$ \\
\hline Males & Overall & Unchanged & Partial & Complete/Near \\
\hline Radiculopathy & $\mathrm{n}(\mathrm{Col} \%)$ & n (Row \%) & n (Row \%) & $\mathrm{n}($ Row \%) \\
\hline Below T10 only & $5(13.51 \%)$ & $0(0.00 \%)$ & $2(40.00 \%)$ & $3(60.00 \%)$ \\
\hline Above and below T10 & $5(13.51 \%)$ & $1(20.00 \%)$ & $2(40.00 \%)$ & $2(40.00 \%)$ \\
\hline Above T10 only & $27(72.97 \%)$ & $3(11.54 \%)$ & $12(46.15 \%)$ & $12(44.44 \%)$ \\
\hline \multicolumn{5}{|l|}{ No Radiculopathy } \\
\hline Below T10 only & $17(19.32 \%)$ & $2(11.76 \%)$ & $8(47.06 \%)$ & $7(41.18 \%)$ \\
\hline Above and below T10 & $17(19.32 \%)$ & $2(11.76 \%)$ & $7(41.18 \%)$ & $8(47.06 \%)$ \\
\hline Above T10 only & $54(61.36 \%)$ & $5(9.09 \%)$ & $22(40.00 \%)$ & $27(50.00 \%)$ \\
\hline
\end{tabular}


Table 4. Ordinal logistic regression results $(\boldsymbol{n}=272)$.

\begin{tabular}{|c|c|c|c|}
\hline Variable & Odds Ratio (OR) & 95\% CI for OR & $P$-value \\
\hline \multicolumn{4}{|l|}{ Intercepts } \\
\hline Intercept for No Resolution & 0.31 & $0.08-1.26$ & 0.1028 \\
\hline Intercept for Partial Resolution & 2.93 & $0.73-11.78$ & 0.1304 \\
\hline \multicolumn{4}{|l|}{ Main Effects } \\
\hline Radiculopathy & 0.70 & $0.42-1.17$ & 0.1753 \\
\hline Age & 0.97 & $0.96-0.99$ & 0.0063 \\
\hline Female Sex & 1.06 & $0.67-1.7$ & 0.7939 \\
\hline Injury above T10 & 2.08 & $1.15-3.75$ & 0.0155 \\
\hline Secondary Osteoporosis & 1.37 & $0.71-2.64$ & 0.3555 \\
\hline Procedure on Two Levels & 1.85 & $1.1-3.1$ & 0.0206 \\
\hline
\end{tabular}

Note 1: Score test for proportional odds assumption, $P=0.1636$ (i.e. proportional odds assumption was not rejected)

Table 5. Ordinal logistic regression predicted probabilities.

\begin{tabular}{|l|c|c|c||}
\hline & $\begin{array}{c}\text { Near Complete/Complete } \\
\text { Resolution Mean } \\
\text { Probability }\end{array}$ & $\begin{array}{c}\text { Partial Resolution } \\
\text { Mean Probability }\end{array}$ & $\begin{array}{c}\text { No Resolution } \\
\text { Mean Probability }\end{array}$ \\
\hline Female, no radiculopathy, fracture below T10 only & 0.5880 & 0.3405 & 0.0715 \\
\hline Female, no radiculopathy, fracture above T10 only & 0.4272 & 0.4445 & 0.1283 \\
\hline Female, no radiculopathy, fracture above and below T10 & 0.3457 & 0.4823 & 0.1720 \\
\hline Female, radiculopathy, fracture below T10 only & 0.6696 & 0.2790 & 0.0514 \\
\hline Female, radiculopathy, fracture above T10 only & 0.5144 & 0.3917 & 0.0939 \\
\hline Female, radiculopathy, fracture above and below T10 & 0.4287 & 0.4437 & 0.1276 \\
\hline Male, no radiculopathy, fracture below T10 only & 0.6015 & 0.3307 & 0.0678 \\
\hline Male, no radiculopathy, fracture above T10 only & 0.4410 & 0.4368 & 0.1222 \\
\hline Male, no radiculopathy, fracture above and below T10 & 0.3586 & 0.4772 & 0.1642 \\
\hline Male, radiculopathy, fracture below T10 only & 0.6819 & 0.2694 & 0.0487 \\
\hline Male, radiculopathy, fracture above T10 only & 0.5284 & 0.3823 & 0.0893 \\
\hline Male, radiculopathy, fracture above and below T10 & 0.4425 & 0.4360 & 0.1215 \\
\hline
\end{tabular}

Note 1: All predicted probabilities were calculated using mean age.

not been well expanded beyond a classic but limited description of focal axial pain at the fracture level (40).

The decision to perform a KP or VP in our study was decided at the discretion of the operating physicians at the point-of-care. Both techniques were used, although substantially more KP were performed because of their improved outcomes and complication profiles, shorter fluoroscopy and sedations times, and comfort level of the operating physician, a trend that is present nationally (41). Additionally, a substantial majority of VP procedures were performed in the first half of the study period. Given this discrepancy in procedure selection, we elected not to perform further subanalysis compari- son of our KP and VP subgroups, although the comparison of KP and VP outcomes, specifically with respect to patients with radiculopathy, remains a necessary focus of further research.

The incidence of dermatomal pain and radiculopathy in patients with VCF undergoing KP and VP is a relatively new concept in the assessment of patients with VCF. Although few articles have identified and described the presence of radicular pain, particularly in lumbar compression fractures, none of these articles clearly defined the incidence of this symptom outside of the lumbar spine or evaluate the expected outcomes following VP and KP treatment (42-44). 
In our study, we identified an estimated overall prevalence of noncompressive radiculopathy in thoracic and lumbar VCFs, and assessed the predicted probability of near complete or complete pain improvement after VP and KP treatment. We found that concordant radiculopathy in the absence of nerve impingement was common in all fracture locations, occurring in $31.6 \%$ of our patients, which is similar to results presented by Kim et al (43). The prevalence of concordant radiculopathy was largely spread across all location subsets (i.e., fractures above or below T10) without any statistically significant predilection for any fracture location. Following the procedure, patients with preprocedural radiculopathy demonstrated increased probability of clinical improvement rated as "near complete" or "complete," as evidenced by higher mean predictive probabilities in both men and women with radiculopathy across all location subsets as compared with those patients without preprocedural radiculopathy. These findings are loosely supported by Kim et al (43) and Bae et al (45), who demonstrated improved post-VP outcomes in a small subset of patients with vertebral compression fractures and preprocedural radicular symptoms.

Following VCF, there are many reasons for axial pain and radiculopathy symptoms to be present in a patient. Focal radiculopathy following a VCF was initially attributed to mechanical compression of the nerve roots from unstable fracture fragments, which leads to the consideration of this symptom as a relative contraindication $(29,45)$. Unlike previous studies, however, we sought to eliminate these confounding etiologies for pain by excluding patients with significant neural foraminal stenosis that could potentially contribute to radicular symptoms, as well as those without preprocedural imaging to exclude the same. With this exclusion, we were able to isolate and evaluate a sizable subset of patients who experienced radicular symptoms without a known mechanical etiology.

We suspect that a large proportion of patients with radicular symptoms in the setting of VCF are experiencing a chemical radiculitis from irritant blood products and proinflammatory cytokines caused by the fracture itself (46). Chemical radiculitis has been described as a mechanism in which an annular disc tear resulted in leaking of nucleus pulposus fluid and subsequent irritation of the adjacent nerve roots $(47,48)$. Using this same reasoning, we believe that blood products within the neural foramen and paraspinal soft tissues may have this same effect on the traversing nerve roots, leading to radicular symptoms. Radicular pain in the setting of VCF may therefore be the result of persistent bleeding from sustained micromotion across the fracture. This potential association between micromotion and radiculopathy could explain the higher probability of pain resolution after VP/KP stabilization in patients with radiculopathy over those without these symptoms.

Limitations of the study include subjective grading of clinical improvement based on clinical notes in the EMR, which is subject to suboptimal symptom reporting. A single definition of radiculopathy was agreed on and used, although the retrospective format of the study required us to apply this definition to provider notes, some of which did not explicitly localize the nerve responsible for the radiculopathy. Although multiple confounding factors were removed, additional confounding variables may exist that were either not present within the EMR or not collected as part of this study. Additionally, each VCF was analyzed independently in our review, although some were new fractures on previously treated patients, even though it is known that a prior VCF is a risk factor for a new nearby VCF (39). Ignoring the correlation between VCFs in the same patient can result in biased estimates and standard errors, but as the number of repeated measures within the same patient was low, generalized linear mixed models did not converge.

Future directions of research include understanding how the actual fracture morphology may contribute to radiculopathy. Although we propose the chemical neuritis theory from associated fracture hemorrhage, further studies may help to understand this relationship based on the extent of perifracture bleeding, especially in the acute setting.

\section{Conclusions}

Preprocedural radiculopathy in the absence of nerve impingement is a common symptom associated with VCFs. Although current guidelines consider radiculopathy as a relative contraindication to VP and $\mathrm{KP}$, we propose noncompressive radiculopathy is in contrast an important marker identifying patients with vertebral compression fracture who trend toward greater postprocedural improvement following VP and KP treatment. 


\section{References}

1. Riggs LR, Melton LJ. The worldwide problem of osteoporosis: Lessons from epidemiology. Bone 1995; 17:2-3.

2. Kado DM, Browner WS, Palermo L, Nevitt MC, Genant HK, Cummings SR. Vertebral fractures and mortality in older women: A prospective study. Arch Intern Med 1999; 159:1215-1220.

3. Nevitt MC, Thompson DE, Black DM, et al. Effect of alendronate on limitedactivity days and bed-disability days caused by back pain in postmenopausal women with existing vertebral fractures. Arch Intern Med 2000; 160:77-85.

4. Fink HA, Ensrud KE, Nelson DB, et al. Disability after clinical fracture in postmenopausal women with low bone density: The fracture intervention trial (FIT). Osteoporos Int 2003; 14:69-76.

5. Voormolen $\mathrm{MH}$, Mali WP, Lohle PN, et al. Percutaneous vertebroplasty compared with optimal pain medication treatment: Short-term clinical outcome of patients with subacute or chronic painful osteoporotic vertebral compression fractures. The VERTOS Study. Am J Neuroradiol 2007; 28:555-560.

6. Boswell MV, Trescot AM, Datta S, et al. Interventional techniques: Evidencebased practice guidelines in the management of chronic spinal pain. Pain Physician 2007; 10:7-111.

7. Zhao S, Xu CY, Zhu AR, et al. Comparison of the efficacy and safety of 3 treatments for patients with osteoporotic vertebral compression fractures: A network metaanalysis. Medicine (Baltimore) 2017; 96:e7328.

8. Baerlocher MO, Saad WE, Dariushnia S, Barr JD, Mcgraw JK, Nikolic B. Quality improvement guidelines for percutaneous vertebroplasty. J Vasc Interv Radiol 2014; 25:165-170.

9. Klazen CA, Lohle PN, de Vries J, et al. Vertebroplasty versus conservative treatment in acute osteoporotic vertebral compression fractures (Vertos II): An open-label randomised trial. Lancet 2010; 376:1085-1092.

10. Boonen S, Van Meirhaeghe J, Bastian L, et al. Balloon kyphoplasty for the treatment of acute vertebral compression fractures: 2-year results from a randomized trial. J Bone Miner Res 2011; 26:1627-1637.

11. McGirt MJ, Parker SL, Wolinsky JP, Witham TF, Bydon A, Gokaslan ZL.
Vertebroplasty and kyphoplasty for the treatment of vertebral compression fractures: An evidenced-based review of the literature. Spine J 2009; 9:501-508.

12. Wilson DR, Myers ER, Mathis JM, et al. Effect of augmentation on the mechanics of vertebral wedge fractures. Spine (Phila Pa 1976) 2000; 25:158-165.

13. Belkoff SM, Mathis JM, Fenton DC Scribner RM, Reiley ME, Talmadge K. An ex vivo biomechanical evaluation of an inflatable bone tamp used in the treatment of compression fracture. Spine (Phila Pa 1976) 2001; 26:151-156.

14. Belkoff SM, Mathis JM, Jasper LE, Deramond $\mathrm{H}$. An ex vivo biomechanical evaluation of a hydroxyapatite cement for use with vertebroplasty. Spine (Phila Pa 1976) 2001; 26:1542-1546.

15. Rousing R, Hansen KL, Andersen MO, Jespersen SM, Thomsen K, Lauritsen JM. Twelve-months follow-up in fortynine patients with acute/semiacute osteoporotic vertebral fractures treated conservatively or with percutaneous vertebroplasty: A clinical randomized study. Spine (Phila Pa 1976) 2010; 35:478-482.

16. Kallmes DF, Comstock BA, Heagerty PJ, et al. A randomized trial of vertebroplasty for osteoporotic spinal fractures. $N$ Engl] Med 2009; 361:569-579.

17. Rousing R, Andersen MO, Jespersen SM, Thomsen K, Lauritsen J. Percutaneous vertebroplasty compared to conservative treatment in patients with painful acute or subacute osteoporotic vertebral fractures. Spine (Phila Pa 1976) 2009; 34:1349-1354.

18. Buchbinder R, Osborne RH, Ebeling PR, et al. A randomized trial of vertebroplasty for painful osteoporotic vertebral fractures. N Engl J Med 2009; 361:557-568.

19. Farrokhi MR, Alibai E, Maghami Z. Randomized controlled trial of percutaneous vertebroplasty versus optimal medical management for the relief of pain and disability in acute osteoporotic vertebral compression fractures. J Neurosurg Spine 2011; 14:561-569.

20. Wardlaw D, Cummings SR, Van Meirhaeghe J, et al. Efficacy and safety of balloon kyphoplasty compared with nonsurgical care for vertebral compression fracture (FREE): A randomised controlled trial. Lancet 2009; 373:1016-1024.
21. Clark W, Goh AC. Vertebroplasty for acute osteoporotic spinal fracturesBest evidence? J Vasc Interv Radiol 2010; 21:1330-1333.

22. Bouza C, López T, Magro A, Navalpotro L, Amate JM. Efficacy and safety of balloon kyphoplasty in the treatment of vertebral compression fractures: A systematic review. Eur Spine J 2006; 15:1050-1067.

23. Garfin SR, Yuan HA, Reiley MA. New technologies in spine: Kyphoplasty and vertebroplasty for the treatment of painful osteoporotic compression fractures. Spine (Phila Pa 1976) 2001; 26:1511-1515.

24. Kasperk C, Hillmeier J, Nöldge G, et al. Treatment of painful vertebral fractures by kyphoplasty in patients with primary osteoporosis: A prospective nonrandomized controlled study. J Bone Miner Res 2005; 20:604-612.

25. Alvarez L, Alcaraz M, Pérez-Higueras $A$, et al. Percutaneous vertebroplasty: Functional improvement in patients with osteoporotic compression fractures. Spine (Phila Pa 1976) 2006; 31:1113-1118.

26. Masala S, Cesaroni A, Sergiacomi G, et al. Percutaneous kyphoplasty: New treatment for painful vertebral body fractures. In Vivo (Brooklyn) 2004; 18:149-154.

27. Rhyne A, Banit D, Laxer E, Odum S, Nussman D. Kyphoplasty: Report of eighty-two thoracolumbar osteoporotic vertebral fractures. J Orthop Trauma 2004; 18:294-299.

28. Lieberman $\mathrm{IH}$, Dudeney $\mathrm{S}$, Reinhardt MK, Bell G. Initial outcome and efficacy of kyphoplasty in the treatment of painful osteoporotic vertebral compression fractures. Spine (Phila Pa 1976) 2001; 26:1631-1637.

29. McGraw JK, Cardella J, Barr JD, et al. Society of interventional radiology quality improvement guidelines for percutaneous vertebroplasty. J Vasc Interv Radiol 2003; 14:827-831.

30. Röllinghoff M, Zarghooni K, SchlüterBrust $K$, et al. Indications and contraindications for vertebroplasty and kyphoplasty. Arch Orthop Trauma Surg 2010; 130:765-774.

31. Trumm CG, Jakobs TF, Zech C), Helmberger TK, Reiser MF, Hoffmann RT. CT Fluoroscopy-guided 
percutaneous vertebroplasty for the treatment of osteolytic breast cancer metastases: Results in 62 sessions with 86 vertebrae treated. J Vasc Interv Radiol 2008; 19:1596-1606.

32. Barr JD, Jensen ME, Hirsch JA, et al. Position statement on percutaneous vertebral augmentation a consensus statement developed by the Society of Interventional Radiology (SIR), American Association of Neurological Surgeons (AANS) and the Congress of Neurological Surgeons (CNS), American College of Radiology (ACR), American Society of Neuroradiology (ASNR), American Society of Spine Radiology (ASSR), Canadian Interventional Radiology Association (CIRA), and the Society of Neurolnterventional Surgery (SNIS). J Vasc Interv Radiol 2014; 25:171-181.

33. Stallmeyer MJB, Zoarski GH, Obuchowski AM. Optimizing patient selection in percutaneous vertebroplasty. ] Vasc Interv Radiol 2003; 14:683-696.

34. Yuan WH, Hsu HC, Lai KL. Vertebroplasty and balloon kyphoplasty versus conservative treatment for osteoporotic vertebral compression fractures. Medicine (Baltimore) 2016; 95: 44491.

35. Dublin AB, Hartman J, Latchaw RE, Hald JK, Reid MH. The vertebral body fracture in osteoporosis: Restoration of height using percutaneous vertebroplasty. Am
J Neuroradiol 2005; 26:489-492.

36. Lee JH, Kwon JT, Kim YB, Suk JS. Segmental deformity correction after balloon kyphoplasty in the osteoporotic vertebral compression fracture.] Korean Neurosurg Soc 2007; 42:371.

37. Rao RD, Singrakhia MD. Painful osteoporotic vertebral fracture. Pathogenesis, evaluation, and roles of vertebroplasty and kyphoplasty in its management. J Bone Joint Surg Am 2003; 85:2010-2022.

38. Wu AM, Li XL, Li XB, et al. The outcomes of percutaneous kyphoplasty in treatment of the secondary osteoporotic vertebral compression factures: A casecontrol study. Ann Transl Med 2018; 6:107.

39. Melton LJ, Kallmes DF. Epidemiology of vertebral fractures: Implications for vertebral augmentation. Acad Radio 2006; 13:538-545.

40. Hoffmann RT, Jakobs TF, Ertl-Wagner BB, Wallnöfer A, Reiser MF, Helmberger TK. Interventionen an der wirbelsäule stellenwert der vertebroplastie bei osteoporotisch bedingten wirbelkörperfrakturen diagnostik und indikationen. Radiologe 2003; 43:729-734.

41. Goz V, Errico TJ, Weinreb JH, et al. Vertebroplasty and kyphoplasty: National outcomes and trends in utilization from 2005 through 2010. Spine J 2015; 15:959-965.
42. Doo TH, Shin DA, Kim $H$, et al. Clinical relevance of pain patterns in osteoporotic vertebral compression fractures.J Korean Med Sci 2008; 23:1005.

43. Kim DE, Kim HS, Kim SW, Kim HS. Clinical analysis of acute radiculopathy after osteoporotic lumbar compression fracture. J Korean Neurosurg Soc 2015; 57:32-35.

44. Chung SK, Lee SH, Kim DY, Lee HY. Treatment of lower lumbar radiculopathy caused by osteoporotic compression fracture: The role of vertebroplasty. J Spinal Disord Tech 2002; 15:461-468.

45. Bae JW, Gwak HS, Kim S, et al. Percutaneous vertebroplasty for patients with metastatic compression fractures of the thoracolumbar spine: Clinical and radiological factors affecting functional outcomes. Spine J 2016; 16:355-364.

46. Mulleman D, Mammou S, Griffoul I, Watier H, Goupille P. Pathophysiology of disk-related sciatica. I. Evidence supporting a chemical component. Joint Bone Spine 2006; 73:151-158.

47. Peng Baogan, Wu Wenwen, Li Zhenzhou, Guo Jidong, Wang Xiaoning. Chemical radiculitis. Pain 2007; 127:11-16.

48. Marshall LL, Trethewie ER, Curtain CC. Chemical radiculitis. A clinical, physiological and immunological study. Clin Orthop Relat Res 1977:61-67. 
